\title{
Efeito do Detoxa Plus $®$ sobre os parâmetros produtivos em galinhas de postura
}

\author{
Fabio Luis Gazoni ${ }^{1}$, Fabrizio Matte ${ }^{1}$, Thalita Malta², Carolini Prigol ${ }^{1}$, Marcel M. Boiago ${ }^{3}$
}

\section{Resumo}

As micotoxinas representam desafios para a indústria de produção de alimentos e, em especial, no uso desses alimentos para a produção de proteína animal. Neste estudo, determinamos os efeitos de adição do inativador enzimático de micotoxinas à base de S. cerevisiae (Detoxa Plus ${ }^{\circledR}$ ) adicionado à ração contaminada com 4 ppm T-2 e 20 ppm FB1. A avaliação contou com 48 poedeiras Hy-line Brown e as dividimos em quatro grupos com quatro repetições por grupo sendo três aves por repetição. Os grupos foram: Controle Negativo (C-), Controle Positivo (C+), Detoxa Plus $®$ - 0,5 kg/ton (C+ DP 0,50) e Detoxa Plus ${ }^{\circledR}$ - 1 kg/ ton (C+ DP 1) com contaminação de T-2 e FB1. O período experimental foi das 25 às 37 semanas de idade das aves. As aves que consumiram ração com Detoxa Plus $₫$ tiveram maior produção de ovos em comparação com o grupo $\mathrm{C}+$. O uso de Detoxa Plus ${ }^{\circledR}$ na alimentação minimizou os efeitos negativos das micotoxinas sobre a taxa de conversão alimentar. As poedeiras que consumiram micotoxinas apresentaram menor resistência e espessura de casca de ovo em comparação com as do grupo C-. Com relação às enzimas hepáticas, houve flutuações quando as aves consumiram micotoxinas, ora reduzindo e ora aumentando; no entanto, o efeito cumulativo aumentou a atividade da alanina aminotransferase. Concluímos que o consumo de micotoxinas prejudicou o desempenho e a qualidade dos ovos e a adição do Detoxa Plus $₫$ minimizou os efeitos negativos causados por 4 ppm T-2 e 20 ppm FB1.

Palavras-chave: Detoxa Plus $®$; micotoxinas; parâmetros produtivos; ovo.

\section{Introdução}

A ração balanceada que é fornecida às galinhas de postura comercial tem impacto de $55 \%$ a $60 \%$ no custo de uma dúzia de ovos. Contaminantes como as micotoxinas causam perdas significativas na qualidade da ração e nos resultados gerais de produção.

As micotoxinas são metabólitos produzidos por diferentes tipos de fungos sob estresse. Esses fungos geralmente contaminam os cereais e produzem toxinas em diferentes pontos da cadeia de produção. Quando as micotoxinas são ingeridas por animais, elas causam várias alterações na saúde que variam de acordo com os tipos e quantidades de micotoxinas ingeridas.

Hoje, se tem disponíveis vários métodos para controlar as micotoxinas. Algumas micotoxinas apresentam uma complexa estrutura química e a maneira mais eficiente de controlá-las é por meio de aditivos enzimáticos anti-micotoxinas. Esses aditivos não dependem da polaridade das micotoxinas, mas agem especificamente sobre elas.

Autores (JOUANY, 2007; ARMANDO, 2012; TSO, 2019) demonstraram que diferentes cepas de Saccharomyces cerevisiae possuem as enzimas necessárias para biotransformar as principais micotoxinas como tricotecenos, ocratoxinas, fumonisinas e zearalenona.

Portanto, neste estudo, realizamos a adição do lisado de $S$. cerevisiae (Detoxa Plus ${ }^{\circledR}$ ) em rações contaminadas com T-2 e
FB1 em poedeiras, avaliando a eficiência produtiva e a qualidade dosovos.

\section{Material e métodos}

\section{Produto avaliado}

O produto comercial usado em nosso estudo foi um lisado com base em S. cerevisiae (86\%) (Detoxa Plus $®$, Vetanco do Brasil Importação e Exportação Ltda).

\section{Micotoxinas}

A produção de Fumonisinas B1 e B2 foi através do isolado de Fusarium verticillioides, que foi cultivado em arroz. A fermentação foi realizada em frascos Erlenmeyer de $500 \mathrm{~mL}$ de capacidade, aos quais foram adicionados $100 \mathrm{~g}$ de arroz. O arroz foi umedecido com água da torneira (atividade deágua $>0,97$ ) e autoclavado $121^{\circ} \mathrm{C}$ por 1 hora. O arroz autoclavado foi inoculado com $2 \mathrm{~mL}$ de uma suspensão de conídios $\left(1 \times 10^{5}\right.$ conídios por $\mathrm{mL}$ ). A suspensão conidial foi obtida a partir de colônias de $F$. verticillioides, crescendo em ágar batata-dextrose por 15 dias a $25^{\circ} \mathrm{C}$. Após a inoculação, os frascos foram mantidos estáticos por 28 dias a $25^{\circ} \mathrm{C}$ e, posteriormente, o fermentado foi seco.

A produção de toxina T-2 foi obtida a partir da fermentação do milho por $F$. sporotrichioides. A fermentação foi realizada em frascos Erlenmeyer de $500 \mathrm{~mL}$ aos quais foram adicionados $100 \mathrm{~g}$ de milho. O milho estava umedecido (atividade de água $>0,97$ )

\footnotetext{
${ }^{1}$ Mestre em Sanidade e Reprodução Animal, Programa de Pós-Graduação em Medicina Veterinária - Universidade Federal de Santa Maria/RS. Coordenador Técnico Comercial América Latina - Aves. Vetanco do Brasil. Rua Raimundo Zanella, 400-D. Distrito Industrial Flávio Baldissera. Chapecó, Santa Catarina, Brazil. 89813-824. E-mail: gazoni@vetanco.com.br

${ }^{2}$ Vetanco do Brasil, Santa Catarina, Chapecó, Brazil.

${ }^{3}$ Universidade do Estado de Santa Catarina, Chapecó, Brazil.
} 
e autoclavado a $121^{\circ} \mathrm{C}$ por 1 hora. Subsequentemente, o milho foi inoculado com $2 \mathrm{~mL}$ de uma suspensão de conídios $\left(1 \times 10^{5}\right.$ conídios por $\mathrm{mL}$ ). A suspensão de conídios foi obtida a partir de Colônias de F. sporotrichioides, crescendo em ágar batatadextrose por 15 dias a $25^{\circ} \mathrm{C}$. Após a inoculação, os frascos foram mantidos estáticos por 28 dias a $25^{\circ} \mathrm{C}$. Posteriormente, o milho fermentado foi seco e moído para ser usado para contaminar artificialmente a ração. As concentrações de Fumonisina e Toxina T-2 nos substratos foi mensurada usando a cromatografia líquida de espectrometria de massa (HPLC/MS/MS).

\section{Desenho experimental}

O experimento foi realizado em um galpão experimental na cidade de Chapecó, SC, ao longo das 25 às 37 semanas de vida das aves, correspondendo a três ciclos produtivos de 28 dias cada. A ração utilizada foi formulada à base de milho e farelo de soja, de acordo com as necessidades nutricionais das galinhas poedeiras (ROSTAGNO, 2017). As 48 galinhas Hy-line Brown, 25 semanas de idade, foram divididas em quatro tratamentos, com quatro repetições por tratamento e três galinhas por repetição. $O$ experimento foi conduzido em um sistema de criação em gaiolas $(0,5 \times 0,6 \times 0,4 \mathrm{~m})$, equipadas com um comedouro tipo calha $\mathrm{e}$ a água fornecida com o bebedouro tipo nipple. O fornecimento de ração e água foi ad libitum.

O projeto foi aprovado pela Comissão de Ética no Uso de Animais (CEUA) da Universidade Estadual de Santa Catarina (UDESC), protocolo número 3089070619, seguindo as recomendações do conselho brasileiro de experimentação com a utilização de animais em pesquisas, bem como respeitando a atuais regulamentos relativos ao bem-estar animal.

Os tratamentos foram identificados da seguinte forma: Controle Negativo (C-), alimentação basal sem micotoxinas; Controle Positivo $(\mathrm{C}+)$, alimentação contaminada com 4 ppm T-2 e 20 ppm FB1; 0,5 kg/ton de Detoxa Plus $®(C+$ DP 0,5$)$ + alimentação contaminada com 4 ppm de T2 e 20 ppm de FB1 e 1 kg/ton de Detoxa Plus $®$ (C+ DP 1) + alimentação contaminada com 4 ppm de T2 e 20 ppm de FB1. A dose de micotoxinas descritas foi calculada com base na concentração do composto inócuo. $A$ concentração real de FB1 e T-2 nas dietas de poedeiras deste estudo está demonstrada na Tabela 1.

\section{Análise estatística}

Todas as variáveis dependentes foram testadas para normalidade usando o Univariate, procedimento do SAS (SAS
Inst. Inc., Cary, NC, EUA; versão 9.4). A significância foi definida quando $\mathrm{p} \leq 0,05$.

\section{Resultados e discussão}

\section{Desempenho produtivo}

No desempenho produtivo (Tabela 2) observamos diferenças estatísticas de $(p \leq 0,05)$ do grupo $C$ - com relação ao grupo $C+$, onde o C- teve maior produção de ovos em todos os períodos comparados. Quando comparamos o grupo C + com os grupos que consumiram o aditivo anti-micotoxina, observamos efeitos positivos; ou seja, houve maior produção de ovos, bem como maior peso e massa. Os efeitos benéficos dos aditivos antimicotoxina como eliminadores de micotoxinas em aves são amplamente conhecidos (BUNZEN, 2006).

As aves que consumiram ração com Detoxa Plus ${ }^{\circ}$, grupos $\mathrm{C}+$ DP 0,5 e C+ DP 1, tiveram maior produção de ovos em todos os períodos (exceto para C+ DP 0,5 ciclo 29-33 semanas) em comparação com o grupo C+.

O grupo C- teve maior consumo de alimento em todos os períodos em comparação com todos os outros grupos (Tabela 2). Com relação ao peso médio, os grupos C-, C+ DP 0,5 e C+ DP 1 não apresentaram diferença estatística $(p \leq 0,05)$.

Com relação a conversão $(\mathrm{kg} / \mathrm{Kg})$, tivemos o melhor desempenho produtivo, de 1.62, no grupo C+ DP 1. No entanto, neste estudo, foi utilizado o Detoxa Plus $\circledR$ que modulou positivamente o sistema de produção usando galinhas poedeiras como modelo experimental. O grupo C- e todos os tratamentos que receberam adsorventes apresentaram maior consumo de ração, ou seja, o consumo de ração no grupo $\mathrm{C}+$ foi reduzido; por outro lado, o uso do Detoxa Plus $\AA$ evitou o efeito negativo relacionado à baixa produtividade e saúde das aves. Um estudo anterior constatou que as lesões orais em aves intoxicadas com T2 evoluem para necrose, erosões e ulcerações na base da língua, no palato e na comissura do bico, reduzindo o consumo de ração e o ganho de peso (SANTIN, 2000).

A suplementação com Detoxa Plus $® 0,5 \mathrm{~kg} / \mathrm{t}$ e $1 \mathrm{~kg} / \mathrm{t}$ teve efeito positivo sobre os parâmetros zootécnicos quando comparado ao $\mathrm{C}+$, melhorando o peso dos ovos em $4,26 \%$ e $7,14 \%$, respectivamente; a porcentagem de postura nos três ciclos de produção, chegando a $12,8 \%$ na $37^{\text {a }}$ semana, além do consumo de ração e a taxa de conversão alimentar em comparação com o controle positivo. Adicionalmente a isto, a administração de Detoxa Plus $®$ gerou aumento na porcentagem de albumina nos ovos (Tabela 3).

Tabela 1: Concentração real de FB1 e T-2 nas dietas deste estudo

\begin{tabular}{|c|c|c|c|}
\hline Grupos & Aditivos & FB1 (ppb) & $\mathrm{T}-2(\mathrm{ppb})$ \\
\hline Controle Negativo (C-) & Sem aditivo & 590 & ND \\
\hline Controle Positivo $(\mathrm{C}+)$ & Sem aditivo & 17.100 & 2.120 \\
\hline Detoxa Plus ${ }^{\circledR} 0,5 \mathrm{~kg} /$ ton $(\mathrm{C}+\mathrm{DP} 0,5)$ & Detoxa Plus $®$ a $0.5 \mathrm{~kg} / \mathrm{ton}$ & 17.450 & 2.410 \\
\hline Detoxa Plus ${ }^{\circledR} 1 \mathrm{~kg} /$ ton (C+ DP 1) & Detoxa Plus $®$ a 1 kg/ton & 16.850 & 2.190 \\
\hline
\end{tabular}

Nota 1: ND - não detectado (Limite de quantificação $30 \mathrm{ppb}$ ). Cromatografia líquida com detecção por espectrometria de massa (HPLC - MS / MS). 
Tabela 2: Desempenho produtivo da postura em aves alimentadas com dietas contendo aditivo adsorvente de micotoxinas

\begin{tabular}{|c|c|c|c|c|c|}
\hline \multirow[b]{2}{*}{ Variáveis } & \multirow[b]{2}{*}{$\begin{array}{c}\text { Ciclos } \\
\text { Semanas }\end{array}$} & \multicolumn{4}{|c|}{ Tratamentos } \\
\hline & & $\mathrm{C}-$ & $\mathrm{C}+$ & $\begin{array}{c}\mathrm{C}+ \\
\text { DP 0,5 }\end{array}$ & $\begin{array}{c}\mathrm{C}+ \\
\text { DP } 1\end{array}$ \\
\hline \multirow{3}{*}{$\%$ de postura } & $25-29$ & $96.25^{\mathrm{a}}$ & $81.84^{c}$ & $86.6^{b}$ & $85.53^{b c}$ \\
\hline & $29-33$ & $92.98^{\mathrm{a}}$ & $85.56^{\mathrm{b}}$ & $84.4^{b}$ & $86.46^{b}$ \\
\hline & $33-37$ & $92.46^{\mathrm{a}}$ & $78.42^{\mathrm{c}}$ & $88.49^{\mathrm{ab}}$ & $86.92^{b}$ \\
\hline \multicolumn{2}{|l|}{ Peso médio do ovo } & $63.86^{\mathrm{a}}$ & $57.92^{b}$ & $60.39^{a b}$ & $62.06^{3}$ \\
\hline \multicolumn{2}{|l|}{ Massa do ovo } & $58.67^{\mathrm{a}}$ & $47.64^{\mathrm{c}}$ & $51.90^{b c}$ & $51.55^{b c}$ \\
\hline \multirow{3}{*}{ Consumo de alimento (CA) } & $25-29$ & $111.77^{3}$ & $78.15^{\mathrm{c}}$ & $94.66^{\mathrm{b}}$ & $80.46^{\mathrm{c}}$ \\
\hline & $29-33$ & $112.51^{3}$ & $84.58^{d}$ & $93.55^{b c}$ & $86.06^{\mathrm{cd}}$ \\
\hline & $33-37$ & $113.25^{2}$ & $90.99^{\mathrm{b}}$ & $92.44^{\mathrm{b}}$ & $91.67^{b}$ \\
\hline \multirow{3}{*}{ Conversão (CA/dúzia) } & $25-29$ & $1.4^{\mathrm{a}}$ & $1.16^{\mathrm{c}}$ & $1.29^{\mathrm{b}}$ & $1.25^{\mathrm{b}}$ \\
\hline & $29-33$ & $1.41^{\mathrm{a}}$ & $1.26^{\mathrm{d}}$ & $1.31^{b c}$ & $1.29^{\mathrm{cd}}$ \\
\hline & $33-37$ & 1.42 & 1.36 & 1.33 & 1.33 \\
\hline \multicolumn{2}{|l|}{ Conversão (kg/kg) } & $1.91^{\mathrm{a}}$ & $1.76^{\mathrm{ab}}$ & $1.78^{\mathrm{ab}}$ & $1.62^{b}$ \\
\hline
\end{tabular}

Diferentes letras (a-b) indicam diferenças significativas entre tratamentos para os diferentes ciclos $\mathrm{p} \leq 0.05$.

\section{Qualidade dos ovos}

$\mathrm{Na}$ qualidade dos ovos (Tabela 3 ), só foram encontradas diferenças significativas $(p \leq 0,05)$ com os tratamentos na porcentagem de albumina, sendo o grupo $\mathrm{C}+\mathrm{DP} 0,5$ com maior quantidade de albumina.

\section{Bioquímica sérica}

$\mathrm{Na}$ avaliação das enzimas hepáticas na triagem da bioquímica sanguínea (Tabela 4), foram observadas diferenças significativas $(p \leq 0,05)$ entre o C- e os demais grupos para os níveis de alanina aminotransferase (ALT) com 37 semanas de idade. A atividade da ALT nas aves pode estar elevada em decorrência de dano em múltiplos tecidos, dificultando muitas vezes a sua interpretação (HARR, 2002).

Os níveis de fosfatase alcalina (Tabela 4), que está associada ao metabolismo do cálcio e fósforo com participação nas atividades osteoblásticas e condrogênicas, foram similares entre tratamentos e controle positivo, mas foram observadas diferenças estatística entre os controles, C- e C+. As alterações nos níveis de fosfatase alcalina suportam a ideia de que o osso medular promove cálcio durante a formação da casca dos ovos e armazena cálcio quando não há ovo no útero (ETCHES, 1987). De acordo com TAYLOR (1965), o nível de fosfatase alcalina que está relacionado às atividades osteoblásticas é maior quando o processo de formação da casca do ovo não está acontecendo.

O desafio das micotoxinas teve impacto negativo sobre as aves, afetando todos os parâmetros zootécnicos, ligeiramente a resistência da casca e os níveis de alanina aminotransferase. Esses resultados indicam que o consumo prolongado de micotoxinas altera os parâmetros zootécnicos, diminui a resistência da casca do ovo e provoca alterações hepáticas, resultando no aumento das enzimas hepáticas no sangue.

Tabela 3: Qualidade de ovos em aves alimentadas com dietas contendo aditivo adsorvente de micotoxinas

\begin{tabular}{l|c|c|c|c}
\hline & \multicolumn{4}{|c}{ Tratamentos } \\
\hline Variáveis & C- & C+ & $\begin{array}{c}\text { C+ } \\
\text { DP 0,5 }\end{array}$ & $\begin{array}{c}\text { C+ } \\
\text { DP 1 }\end{array}$ \\
\hline Resistência da casca, x10 & $5302.84^{\mathrm{a}}$ & $4959.74^{\mathrm{ab}}$ & $4483.13^{\mathrm{b}}$ & $4637.33^{\mathrm{ab}}$ \\
\hline Espessura da casca (mm) & 0.38 & 0.37 & 0.37 & 0.36 \\
\hline Porcentagem da casca & 9.99 & 9.90 & 9.42 & 9.65 \\
\hline Porcentagem de albumina & $63.68^{\mathrm{b}}$ & $63.5^{\mathrm{b}}$ & $65.32^{\mathrm{a}}$ & $64.19^{\mathrm{ab}}$ \\
\hline Porcentagem de gema & 26.14 & 26.88 & 25.67 & 26.2 \\
\hline Diferentes letras (a-b) indicam diferenças significativas entre tratamentos para os diferentes ciclos $\mathrm{p} \leq 0.05$.
\end{tabular}

Tabela 4: Bioquímica sérica em aves alimentadas com dietas contendo aditivo adsorvente de micotoxinas

\begin{tabular}{|c|c|c|c|c|c|}
\hline \multirow[b]{2}{*}{ Variáveis } & \multirow[b]{2}{*}{$\begin{array}{c}\text { Ciclo } \\
\text { Semanas }\end{array}$} & \multicolumn{4}{|c|}{ Tratamentos } \\
\hline & & $\mathrm{C}-$ & $\mathrm{C}+$ & $\begin{array}{c}\mathrm{C}+ \\
\text { DP 0,5 }\end{array}$ & $\begin{array}{c}\text { C+ } \\
\text { DP } 1\end{array}$ \\
\hline \multirow{4}{*}{$\begin{array}{l}\text { Alanina aminotransferase (ALT) } \\
(\mathrm{U} / \mathrm{L})\end{array}$} & 24 & 24.17 & 27.74 & 28.02 & 29.36 \\
\hline & 29 & $18.97^{\mathrm{ab}}$ & $16.36^{\mathrm{ab}}$ & $8.74^{\mathrm{b}}$ & $22.19^{\mathrm{a}}$ \\
\hline & 33 & 17.57 & 9.99 & 7.88 & 10.78 \\
\hline & 37 & $8.28^{\mathrm{b}}$ & $41.90^{\mathrm{a}}$ & $32.22^{\mathrm{a}}$ & $33.87^{\mathrm{a}}$ \\
\hline \multicolumn{2}{|l|}{ Fosfatase alcalina (U/L) } & $509.68^{\mathrm{a}}$ & $343.31^{\mathrm{b}}$ & $451.89^{\mathrm{ab}}$ & $350.07^{\mathrm{b}}$ \\
\hline \multicolumn{2}{|l|}{ Proteínas totais $(\mathrm{mg} / \mathrm{dL})$} & 5.06 & 4.82 & 5.05 & 5.20 \\
\hline \multicolumn{2}{|l|}{ Albuminas totais (mg/dL) } & 1.92 & 1.85 & 1.76 & 1.91 \\
\hline \multicolumn{2}{|l|}{ Globulinas totais $(\mathrm{mg} / \mathrm{dL})$} & 3.14 & 3.01 & 3.29 & 3.30 \\
\hline
\end{tabular}

Diferentes letras (a-b) indicam diferenças significativas entre tratamentos para os diferentes ciclos $p \leq 0.05$. 


\section{Conclusão}

Detoxa Plus $®$ melhorou os parâmetros produtivos das aves desafiadas com FB1 e de T-2 durante três ciclos de 28 dias, das

\section{Referências}

ARMANDO, M. R., PIZZOLITTO, R. P., DOGI, C. A., CRISTOFOLINI, A., MERKIS, C. V., POLONI, C. V., DALCERO, A. M., CAVAGLIERI, L. R., Adsorption of ochratoxin A and zearalenone by potential probiotic Saccharomyces cerevisiae strains and its relation with cell wall thickness. Journal of Applied Microbiology. v. 113, n. 2, p.256-264. 2012.

BUNZEN, S.; HAESE, D. Controle de micotoxinas na alimentação de aves e suínos. Revista Eletrônica Nutritime. v. 3, n. 1, p.299304. 2006.

ETCHES, R. J. Calcium logistics in the laying hen. Journal of Nutrition, v. 117, n.3, p.619-628. 1987.

HARR, K. E. Clinical chemistry of companion avian species: a review. Veterinary Clinical Pathology, Santa Barbara, v. 31, n. 3, p. 140-151, 2002.

JOUANY, J. P. Methods for preventing, decontaminating and minimizing the toxicity of mycotoxins in feeds. Animal Feed Science and Technology, v. 137, n. 3, p.342-362. 2007.
25 às 37 semanas de idade e, ao mesmo tempo, aumentou as porcentagens de albumina nos ovos. Portanto, que Detoxa Plus $®$ nas doses observadas é uma opção viável para o controle dos efeitos deletérios das micotoxinas.

ROSTAGNO, H. S.; ALBINO, L. F. T.; HANNAS, M. I.; DONZELE, J. L.; SAKOMURA, N. K.; PERAZZO, F. G.; SARAIVA, A.;

TEIXEIRA, M. L.; RODRIGUES, P. B.; OLIVEIRA, R. F.

BARRETO, S. L. T.; BRITO, C. O. Tabelas brasileiras para aves e suínos: composição de alimentos e exigências nutricionais. 4ed, Minas Gerais: Universidade Federal de Viçosa, Departamento de Zootecnia.UFV, 2017.

SANTIN, E.; MAIORKA, A.; ZANELLA, I.; MAGON, L. Micotoxinas do Fusarium spp. na avicultura comercial. Ciência Rural, v. 31, n.1, p.185-190. 2000.

TAYLOR, T. G, DACKE, C. G. Calcium metabolism and its regulation. In Physiology and Biochemistry of the Domestic Fowl, vol. 5; ed. F. M. Freeman. London: Academic Press, 1984.

TSO, K. -H.; JU, J. -C.; FAN, Y. -K.; CHIANG, H. -I. Enzyme Degradation Reagents Effectively Remove Mycotoxins Deoxynivalenol and Zearalenone from Pig and Poultry Artificial Digestive Juices. Toxins.v. 11, n. 10, p.599. 2019. 